\title{
Arts of the States in Crisis: Revisiting Determinants of State-Level Appropriations to Arts Agencies
}

\section{Douglas S. Noonan}

\section{Introduction}

Public funding for the arts in the United States occupies an important and controversial niche in the country's cultural sector. Yet while direct arts funding from the government has long been a minor share of resources invested in the arts, it has served as a lightning rod for political controversy, a litmus test for the health of the sector, and a priority-setter and pivotal supporter for particular arts projects and programs. Noonan (2007) offers a detailed look at how fiscal, institutional, and demographic factors influence state-level appropriations to state arts agencies (SAAs) in the United States. His dynamic panel data statistical model relies on data spanning 1969 - 2002. By ending the analysis in 2002, however, the analysis misses one of the most dramatic, challenging, and high-profile eras of public arts funding in the United States. This analysis revisits the earlier study and updates the data through 2011. The past 10 years bring some trends previously not experienced in the data, including the Great Recession $(2007$ - 2009) and declines in appropriations and household income. 2001 marked the all-time peak of funding for SAAs in real terms, and concluding the time series shortly after that point meant that the data only contained what was a familiar story for public arts expenditures around the world: seemingly continually rising funding levels for 30 years. Extending the time series out to 2011 reveals the pattern of nearly monotonic increases in annual appropriations has been supplemented by declines in the real budgets of SAAs in nine out of the past 11 years.

How predictable were recent trends and how determinants of public arts funding have evolved can be informed by comparing the results from Noonan (2007) with new results using an updated set of data and statistical estimation. Some political, economic, and social factors' roles are clearly changed with the updating. The changes in political and fiscal factors' roles are the most notable, with the relative consistency in major socio-economic influences also reflecting important realities for public arts funding in the U.S. Updating the Noonan (2007) study makes several important contributions to the literature. First, it presents 
new findings about the fate of state arts funding during a particularly severe macroeconomic shock. Second, its out-of-sample predictions using the Noonan (2007) model allow for a test of predictability of those prior results. Third, updating the model explaining SAA funding brings in new information and identifies how the determinants of public funding have changed

The analysis proceeds in three steps. The first step is to review the recent experiences for SAA budgets, quantitatively and qualitatively, to describe the recent trends. Second, the Noonan (2007) model is used to forecast trends in funding over recent, post Great-Recession years. By essentially forecasting history, the forecasts can be compared to actual SAA appropriations to reveal how the funding relationships have changed over the past decade. The third step provides new estimates of the determinants of state arts agency appropriations, which are directly compared to the older estimates. Updating these results highlights the new, stronger forces in explaining public funding for the arts in the US. Overall, the analysis illustrates how the dramatic changes in the macroeconomic landscape over the past decade have influenced both the level of SAA funding as well as revealed new drivers of that funding. I conclude by discussing the stability and resilience of US public arts funding.

\section{Background}

The public arts funding system in the US can be briefly summarized as diverse and decentralized (NEA 2012). ${ }^{1}$ There is direct spending from federal, state, and local agencies. There is also indirect support, largely in the form of forgone tax revenues from subsidizing some private arts support. Starting at the federal level, direct spending flows predominantly through the NEA. Created in 1965, the NEA channels a large share (40\% presently) to state arts agencies (SAAs) for more decentralized distribution. ${ }^{2}$ The NEA relies on SAAs to allocate the bulk of its spending that goes directly to artists, helping to insulate the agency from political

\footnotetext{
${ }^{1}$ NEA (2012, p.3): "Direct public support is not used to impose arts policy. Instead, government decisions on arts funding tend to be driven by experts in a given field or discipline. Candidates for those funds are almost always subject to rigorous peer review, which ensures that the awards are based on merit, not on policy aims or on political favoritism." ${ }^{2}$ More background on SAAs can be found in Lowell (2004), Mulcahy (2002), and Schuster (2002).
} 
pressures at the national stage where arts funding, and support for particular artists or art forms, can be contentious. To move funds through the states, however, a system of SAAs needed to be created - and only a handful of states had SAAs at the time of the NEA's inception. A requirement that NEA funds assigned to states be controlled by an NEA-approved SAA and that the state government also match the federal dollars had rapid and important effects. Shortly after the NEA began transferring funds to state agencies (Moore and Moore 2005), all 50 states created SAAs and started receiving funds. They also went well beyond matching NEA transfers with their own appropriations.

Over the past several decades, the states, through their SAAs, became significant sources for public arts support. They managed $\$ 345$ million in fiscal year 2011 , with state appropriations just over $\$ 250$ million (NASAA 2011). The trends in SAA funding levels can be seen in Figure 1.

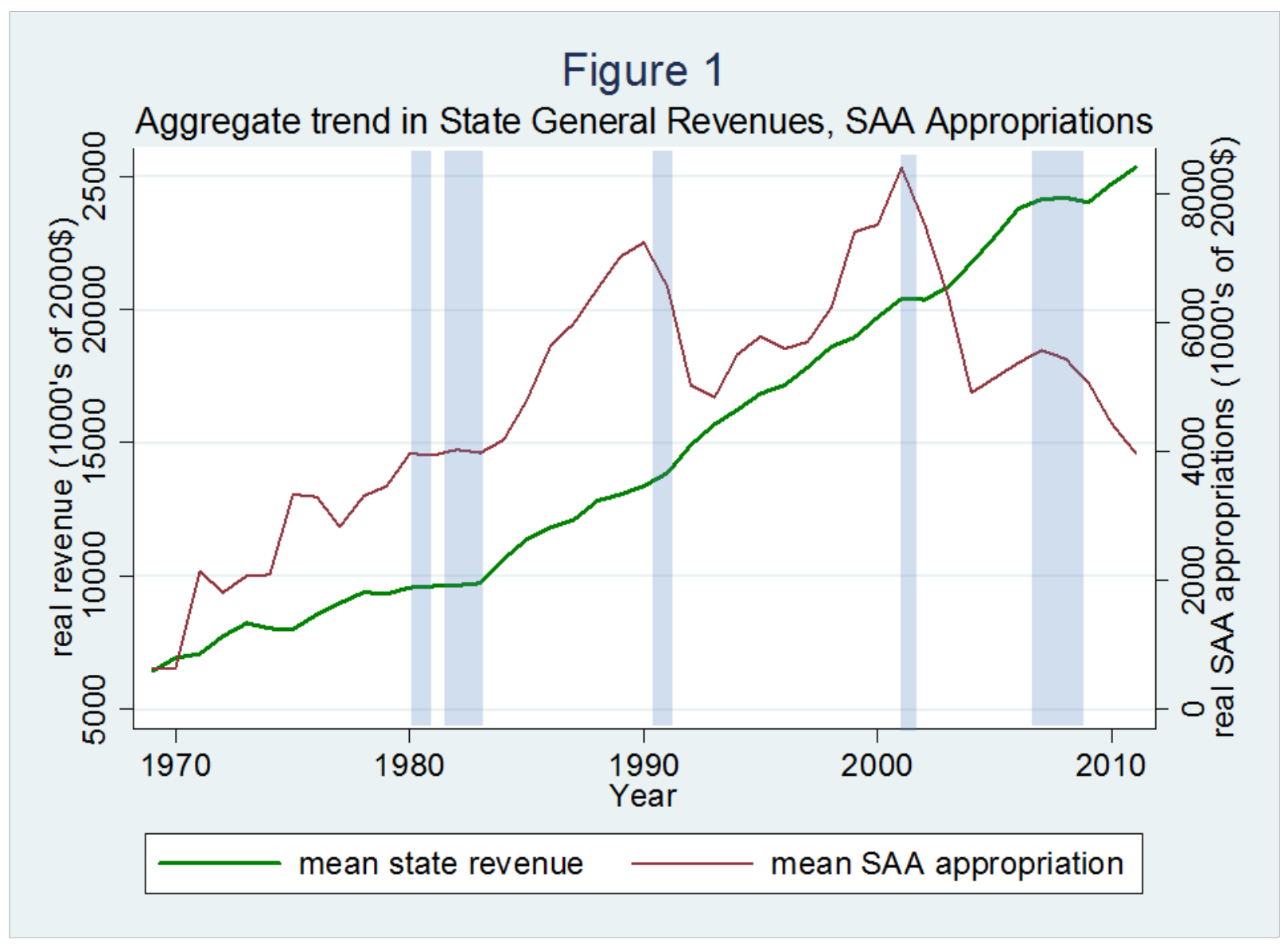


The steady rise in average general state revenues (in constant 2000 US dollars) since 1969 is perhaps the most dramatic aspect of Figure 1. While real NEA grants to the SAAs have remained modest relatively flat, the size of state governments has grown consistently and rapidly over the past 40 years. Meanwhile, the very rapid rise of funding to SAAs after the NEA was formed has proved more volatile after 1990. SAA appropriations in real dollars peaked in 2001 before declining fairly dramatically over the past decade. If the SAA appropriations were scaled in per-capita terms, then the picture in Figure 1 does not change appreciably because these funding trends are all much more dynamic than state population change. It is important to realize that if one ignores the post-2002 data points in Figure 1, then the story told by those trendlines is radically different. When Noonan (2007) examined the data up to 2002, the experience up to that point was characterized by strong but inconsistent upward trends in SAA budgets. Extending the data another ten years now shows more balance (i.e., persistent budget declines also evident) and more volatility.

The volatility in Figure 1 points to an important underlying role of the greater business cycle in the US. Gray vertical bars in Figure 1 represent when each of the official recessions occurred in the US since 1969.3 The longest and deepest recession is the most recent "Great Recession." The patterns in Figure 1 depict a strongyet-imperfect relationship between the US business cycles and public funding of SAAs. Note how recessions since 1990 have all coincided with the initial periods of prolonged declines in SAA funding. In each of those cases, funding declines have extended significantly longer than the duration of the recession. Even relatively minor recessions in 1991 and 2001 precipitated relatively massive SAA appropriation cuts. Recessions have not been good for SAA budgets, and their "hangovers" have been troubling too. But general economic recovery has also spilled over into SAA budgets, and their resilience has been impressive. Pre-2000 recessions have been met with stagnation or decline in SAA appropriations, but subsequent budget growth has been robust enough to restore SAA appropriations to their previous trajectory within a few years. That pattern no longer appears to hold after the 2001 recession. And while SAAs' budget might have started

\footnotetext{
${ }^{3}$ Recessions occurred in the following years (with declines in GDP indicated in parentheses): 1980(-2.2\%); 1981-1982 (2.7\%); 1990-1991 (-1.4\%); $2001(-0.3 \%) ; 2007-2009(-5.1 \%)$.
} 
recovering after the "dot-com bust" recession of 2001, the onset of the Great Recession short-circuited any real recovery and brought average real SAA appropriations back to 1985 levels. ${ }^{4}$

The worldwide economic downturn from 2008 - 2009 presented a fiscal crisis for governments in the US, in particular state governments. Gordon (2012) describes the challenges they faced in the Great Recession, when tax revenues declined at unprecedented rates while demands placed on public support systems grew. Extensive spending cuts followed as all but two states experienced budget shortfalls (Oliff et al. 2012). During the Great Recession, the health of the public arts funding system in the United States appeared at risk of collapse. The Kansas governor eliminated that state's SAA and vetoed appropriations to it. He went so far as to issue layoff notices to all SAA personnel despite the state legislature approving funding for it. South Dakota reduced to zero the appropriations to its SAA in 2010, followed by Arizona eliminating its ArtShare Endowment and general appropriations. In 2010, Michigan's Council for the Arts and Cultural Affairs lost $80 \%$ of its appropriations and the parent agency was eliminated. Extreme funding cuts were commonly proposed, and even enacted in some instances, in many of the states. Table 1 gives an overview of some states that experienced massive funding cuts or attempts to dismantle their state arts agency.

Table 1: Severe SAA funding cuts, actual and proposed, during and after the Great Recession

\begin{tabular}{|ll|ll|}
\hline Largest cuts & cut & Other large cuts \\
\hline State & governor eliminated the SAA entirely & State & cut \\
\hline Kansas (2011) & $\begin{array}{l}100 \% \text { funding reduction } \\
\text { (only funding through business license revenues) }\end{array}$ & Wisconsin (2011) & $68 \%$ \\
\hline Arizona (2011) & $\begin{array}{l}100 \% \text { funding reduction } \\
\text { (only funding through tourism tax) }\end{array}$ & Illinois (2009) & $52 \%$ \\
\cline { 1 - 2 } South Dakota (2010) & $100 \%$ cut (directed to spend from capital in its trust) & Texas (2012) & $50 \%$ \\
\hline Missouri (2011) & $83 \%$ cut & Ohio (2010) & $47 \%$ \\
\hline Louisiana (2009) & $80 \%$ cut and disbanded SAA & Nevada (2010) & $43 \%$ \\
\hline Michigan (2010) & $\begin{array}{l}\text { House of Representatives recommended eliminating } \\
\text { New Hampshire (2011) }\end{array}$ & & \\
\cline { 1 - 2 } South Carolina (2011) & governor recommended eliminating SAA & & \\
\hline Washington (2011) & governor recommended eliminating SAA & & \\
\cline { 1 - 2 } Texas & governor recommended eliminating SAA & & \\
\hline
\end{tabular}

\footnotetext{
${ }^{4}$ The most recent years of SAA appropriations $(2012$ - 2014) show two more years of declining average funding before a funding increase in 2014 .
} 
In fiscal year 2010, six states' SAAs overcame efforts to entirely eliminate them. In Minnesota and South Dakota, the funding for the SAAs was shifted from annual appropriations from the general fund to dedicated earmarks from a special tax. In 2011, four states' SAAs likewise fended off attempts to dismantle them, although restructuring and severe appropriations declines still occurred.

Hard economic times pose funding challenges for many public services, and the arts may not be "special" in this regard. Several previous studies have examined drivers of public arts funding (e.g., Getzner 2002, Werck et al. 2008, Benito et al. 2013, Bertelli et al. 2014). How the arts have fared in light of this new challenge, the deeper and longer "shock" to the fiscal health of the government support system, is ultimately an empirical question. This analysis provides evidence of which factors explain a major category of public arts funding funding to states arts agencies - and assesses how those influences have evolved in light of harsh financial realities of recent years.

\section{Data and Methods}

Noonan (2007) provides the most detailed and rigorous quantitative analysis of SAA funding determinants to date. Noonan explains the variation in SAA funding levels with data on SAA budgets, state fiscal conditions, state socioeconomic measures, and political composition. That study employs an Arellano-Bond (1991) dynamic panel data estimator. This approach allows for previous years' funding levels (and values of other explanatory variables from previous years) to help explain current funding. This approach captures momentum in funding while also explicitly addressing the reality of interdependence in funding levels over time. This panel data approach also recognizes that some states might differ from each other for reasons that are not observed by the researcher or not otherwise explained in the model. The focus instead is on the trends from year-to-year as some states experience different dynamics from others. In the end, Noonan (2007) reports on state-specific measures that describe the arts-friendliness of funding over the decades, controlling for all the other observed factors. 
The results also highlight which factors play the most important roles in explaining SAA funding. Past appropriations, past state revenues and NEA grants, certain demographic variables, and party control of state government all proved to have strong explanatory power. Aside from vague conclusions like "fiscal pressures, institutional rules, and changing constituencies all play important roles in state arts agency funding," (p.308) several more specific results appear. SAA appropriations have considerable momentum from year-to-year, and more NEA grants appear to attract more state funds rather than crowd them out. Rising income helps drive SAA budget growth. Downward time trends are also evident, especially around electoral cycles. The evidence did not support the concern that SAAs fare especially badly during economic downturns, although this might result more from insufficiently severe recessions pre-2003 than from any actual resilience. This article sheds light on this by updating the analysis.

I start with the dataset used by Noonan (2007) and then update each of the variables to $2011 .{ }^{5}$ Table 2 lists the variables. By extending the data through 2011, the extra decade effectively adds $30 \%$ more data points to the analysis. Though sizable in its own right, this extension of the data is not likely just "more of the same." The past 10 years bring some trends in the data previously not experienced as evident in Figure 1. This includes persistent declines in SAA appropriations and stagnating income growth rates. (The slowest average ten-year growth rates in $S A A_{t}$ and Income occurred in 2012 and 2010, respectively.) Furthermore, this period in the US has been associated with considerable political change and demographic shifts as well. Throughout the past ten years, as noted earlier, state arts agencies and their appropriations have attracted considerable attention from the media and public (e.g., Pogrebin 2011). The massive cuts for some SAAs, experienced or proposed, are part of this updated dataset and offer opportunities to identify how previous estimates of the determinants of SAA appropriations stand the test of time. Has the last decade reinforced the previous relationships or ushered in a regime change?

\footnotetext{
${ }^{5}$ The variables are the same as the Noonan (2007) dataset except as updated through 2011. This also updates the imputation of College, which now has more years of data with which to improve the fit for the imputed pre-1993 years.
} 
Table 2: Variable definitions and descriptive statistics

\begin{tabular}{|c|c|c|c|c|}
\hline Variable & Mean & Std.Dev & Description & Source \\
\hline $\mathrm{SAA}_{\mathrm{t}}$ & 14.46 & 1.38 & log of real SAA appropriations in year $t$ & NASAA (2013) \\
\hline Revenuet & 16.04 & 1.00 & log of real general revenues in year $t$ & (a), various years \\
\hline Debt $_{t}$ & 15.36 & 1.20 & log of real debt outstanding in year $t$ & (a), various years \\
\hline $\mathrm{NEA}_{t}$ & 13.15 & 0.38 & log of real NEA grants to state & NASAA (2013) \\
\hline Population & 14.97 & 1.02 & $\begin{array}{l}\text { log of population (estimates for intercensal } \\
\text { years) }\end{array}$ & (b) \\
\hline Density & 0.06 & 0.07 & Population per acre & (a), 2013 \\
\hline Black & 0.10 & 0.09 & proportion of population that is Black & (b) \\
\hline Other & 0.06 & 0.10 & $\begin{array}{l}\text { proportion of population that is nonwhite, and } \\
\text { non-Black }\end{array}$ & (b) \\
\hline Youth & 0.30 & 0.04 & proportion of population that is aged $\leq 19$ & (b) \\
\hline Elders & 0.14 & 0.15 & proportion of population that is aged $>65$ & (b) \\
\hline College & 0.21 & 0.06 & $\begin{array}{l}\text { proportion of population aged > } 25 \text { with } \\
\text { Bachelor's degree or higher, imputed }\end{array}$ & (b), (c) \\
\hline Income & 10.08 & 0.23 & log of real personal income (per capita) & BEA (2013) \\
\hline RGovGrid & 0.09 & 0.29 & $\begin{array}{l}\text { dummy for Republican governor, divided } \\
\text { legislature }\end{array}$ & (a), various years \\
\hline DGovGrid & 0.10 & 0.29 & $\begin{array}{l}\text { dummy for Democrat governor, divided } \\
\text { legislature }\end{array}$ & (a), various years \\
\hline RGovDiv & 0.18 & 0.39 & $\begin{array}{l}\text { dummy for Republican governor, Democrat } \\
\text { legislature }\end{array}$ & (a), various years \\
\hline DGovDiv & 0.30 & 0.46 & $\begin{array}{l}\text { dummy for Democrat governor, Republican } \\
\text { legislature [omitted category] }\end{array}$ & (a), various years \\
\hline RUnified & 0.15 & 0.36 & $\begin{array}{l}\text { dummy for Republican governor, Republican } \\
\text { legislature }\end{array}$ & (a), various years \\
\hline DUnified & 0.30 & 0.46 & $\begin{array}{l}\text { dummy for Democrat governor, Democrat } \\
\text { legislature }\end{array}$ & (a), various years \\
\hline Turnout (\%) & 0.49 & 0.09 & voter turnout (\%) for last presidential election & (a), various years \\
\hline Origin Year & -3.81 & 9.90 & year state established its SAA - 1969 & various SAA websites \\
\hline BalanceBudg & 1.46 & 0.64 & $\begin{array}{l}\text { categorical }[0-2] \text {, with } 2 \text { indicating strictest } \\
\text { budget rules }\end{array}$ & ACIR (1987) \\
\hline \multicolumn{3}{|c|}{$\begin{array}{l}\text { Term Year 1, Term Year 2, Term } \\
\text { Year } 3\end{array}$} & $\begin{array}{l}\text { dummy for first, second, or third year in the } \\
\text { presidential term (e.g., Term Year } 2=1 \text { for 2005) }\end{array}$ & \\
\hline \multicolumn{5}{|c|}{$\begin{array}{l}\text { Key: (a) Statistical Abstract of the United States, years as indicated. } \\
\text { (b) US Census: https://www.census.gov/popest/data/historical/index.html } \\
\text { (c) Author's calculations. Data collected from reports of the Current Population Survey published by } \\
\text { the Census for 1970,1980,1989, 1990,1993-2011. Missing values imputed using state-by-state } \\
\text { regressions with predictors: real per capita income, Youth, and the high school graduation rate, and a } \\
\text { time trend. }\end{array}$} \\
\hline
\end{tabular}

To highlight if and how public arts funding determinants have changed through the Great Recession, I

perform two types of data analysis next. The first step uses the Noonan (2007) estimates of the determinants 
of SAA funding to generate out-of-sample predictions about how SAA appropriations would fare during the Great Recession. Essentially, I use the knowledge of the actual 2007 to 2011 changes in determinants and Noonan's (2007) parameter estimates to calculate a predicted change in SAA appropriations. (This change, from 2007 to 2011, is chosen because 2007 marks the start of the Great Recession and extending to 2011 is both the most recent year with complete data and is sufficient to contain all the lagged values in the estimated equation.) I then compare the predicted changes in appropriations to the actual, experienced changes and describe where the models might have fallen short.

The second step re-estimates the Noonan (2007) models using the updated dataset and observes how key determinants have changed over the past decade in the US. In order to maximize the comparability (and avoid a possibility that model specification changes could account for changes in the results), this analysis also employs an Arellano-Bond dynamic panel data estimator with the same specification. Exactly as Noonan (2007) did, the determinants of SAA funding are estimated based on the fundamental relationship:

$$
Y_{i t}=\alpha_{i}+\beta_{t}+\rho Y_{i t-1}+\psi C_{i t}+\omega I_{i t}+\gamma T_{i t}+\tau H_{i t}+v_{i}+\eta_{i t}
$$

This explains the log of SAA appropriations $(Y)$ in state $i$ in year $t$ by lagged appropriations, political composition variables $(C)$, institutional context $(I)$, and economic and demographic factors $(T)$, in addition to historical variables $(\mathrm{H})$ and time effects $\left(\beta_{t}\right)$ and a state-level disturbance term $\left(v_{i}\right)$. The model assumes a white noise error term $\eta_{i t}$ that is serially uncorrelated. Equation 1 is estimated in first-differences, as follows:

$$
\begin{aligned}
& Y_{i t}-Y_{i t-1}=\beta+ \rho\left(Y_{i t-1}-Y_{i t-2}\right)+\psi\left(C_{i t}-C_{i t-1}\right)+ \\
& \omega\left(I_{i t}-I_{i t-1}\right)+\gamma\left(T_{i t}-T_{i t-1}\right)+\tau\left(H_{i t}-H_{i t-1}\right)+\eta_{i t}-\eta_{i t-1} .
\end{aligned}
$$

While differencing controls for the state-level disturbance $v$, it introduces endogeneity in the lagged difference in $Y_{i t}$ (as $Y_{i t-1}$ will be correlated with $\left.\eta_{i t-1}\right)$. Arellano and Bond (1991) identify many instrumental variables available to estimate (2) via GMM to obtain consistent parameter estimates. The Arellano-Bond estimator instruments with lagged levels of the dependent variable $\left(Y_{i t}\right)$ and predetermined variables $(H)$ as well as differences in the strictly exogenous $(C, I, T)$ variables. The estimator's consistency depends on the absence of second-order autocorrelation such that $\mathrm{E}\left[\left(\eta_{i t}-\eta_{i t-1}\right)\left(\eta_{i t-2}-\eta_{i t-3}\right)\right]=0$ even as $\mathrm{E}\left[\left(\eta_{i t}-\eta_{i t-1}\right)\left(\eta_{i t-2}-\eta_{i t-3}\right)\right] \neq 0$. The 
validity of the instruments can be assessed via a Sargan test of overidentifying restrictions. The empirical approach employed here mimics that of Noonan (2007), including the same assumptions about strictly exogenous variables being uncorrelated with past and current errors. The exogeneity seems reasonable if SAA appropriations are too minor to cause shifts in statewide measures of fiscal health, demographics, and political composition. This approach also uses the previous two years' fiscal variables to allow for slowchanging fiscal effects. Others (e.g., Benito et al. 2013, Nogare and Galizzi 2011) have used dynamic panel data estimators like this one to explain public cultural expenditures, using a lagged dependent variable and one or no lags of other factors.

Just as in Noonan (2007), a second model is also estimated that includes state-level fixed effects. This approach works in a first-differenced framework through implicitly interacting the state fixed effects with a time trend variable. This implies an interpretation for the fixed effects as the persistent differential growth rate in appropriations for that state - relative to the omitted state(s). In Noonan (2007), Nebraska was the omitted state. In the Model 2 estimated here, it is Nebraska and West Virginia and Wyoming, because the Arellano-Bond estimator is over-fitting the model for the latter two states.

\section{Results}

Before examining the out-of-sample predictions in the second stage of this analysis, a table with the variables used and some descriptive statistics is presented. Table 2 indicates identical definitions and very similar values as seen in Noonan (2007). Dollars are adjusted to 2000 US\$.

To obtain the out-of-sample predictions from the Noonan (2007) model estimates, the 2007-2011 changes in values of the explanatory variables in his models are used to predict the average change in SAA funding levels. Table 3 presents the results. The first column indicates how each of the explanatory variables changed from 2007 to 2011. The middle column indicates the predicted change in $S A A_{t}$ due to the change in the 
explanatory variable in the first column. In other words, this column has $b \Delta X$, where $\Delta X$ is the change for variable $X$ in each row and $b$ is its corresponding parameter estimate from Table 2 in Noonan (2007, p.302). The righthand column does likewise for Model 2 parameter estimates with state fixed effects. The bottom row aggregates the predicted changes into a total change. Noonan's earlier estimates do predict a large decline in SAA appropriations given the experienced shifts in other variables, but Model 1 clearly underpredicts the severity of the cuts. While average state arts agency appropriations declined by over $27 \%$ during that recessionary period, the older Model 1 predicts a total reduction in appropriations of only 13\% based on the experienced shifts in the determinants in the models. That the funding cuts were double what might have been predicted going into the recession underscores the dramatic nature of the cuts these agencies have experienced. Model 2, with state-specific time trends, provides a much more accurate out-of-sample prediction.

Table 3 decomposes the total predicted funding decrease into the various contributing elements. Much of the predicted reductions in appropriations come from two factors. First, the cuts in SAA appropriations that started from 2008-2009 had a pronounced negative effect through the lagged term. The big drop in prior SAA appropriations, $-11.6 \%$, predicts an $8.7 \%$ funding decline. Budget cuts to SAAs during the recession became compounded as momentum built against funding the agencies. Second, the general negative time trend observed in the data accounts for most of the predicted loss in funding. Most of Model 1's predicted $13 \%$ decrease comes from the negative time trend of $-2.3 \%$ per year, which accumulates to a predicted $9.2 \%$ decrease over these four years. Again, based on pre-2003 data only, previous models showed an underlying negative time trend in funding, implying that only through improving fiscal and socioeconomic conditions from 1969 - 2001 have SAAs been able to overcome this background negative trend. During the Great Recession, those improvements stopped. Model 2 predicts an especially strong negative time trend. 
Table 3: Out-of-sample predictions and select explanatory factors

\begin{tabular}{|c|c|c|c|}
\hline & & Model 1 & Model 2 \\
\hline Variable & \begin{tabular}{|l|} 
Change \\
$(2007-2011)$
\end{tabular} & $\begin{array}{l}\text { Predicted influence } \\
\text { on SAA spending } \\
(2007-2011)\end{array}$ & $\begin{array}{l}\text { Predicted influence } \\
\text { on SAA spending } \\
(2007-2011)\end{array}$ \\
\hline $\mathrm{SAA}_{\mathrm{t}-1}$ & -0.116 & $-0.087^{* * *}$ & $-0.074^{* * *}$ \\
\hline Revenue $_{\mathrm{t}}$ & +0.059 & 0.006 & $0.010^{* *}$ \\
\hline Revenue $_{\mathrm{t}-1}$ & +0.062 & 0.004 & $0.011^{* *}$ \\
\hline Revenue $_{\mathrm{t}-2}$ & +0.079 & -0.004 & $0.005^{*}$ \\
\hline Debt $_{t}$ & +0.080 & -0.002 & -0.004 \\
\hline Debt $_{t-1}$ & +0.156 & -0.006 & $-0.009^{*}$ \\
\hline Debt $_{t-2}$ & +0.172 & $0.009^{* *}$ & $0.010^{* *}$ \\
\hline $\mathrm{NEA}_{\mathrm{t}}$ & +0.138 & $0.018^{* *}$ & $0.014^{*}$ \\
\hline $\mathrm{NEA}_{\mathrm{t}-1}$ & +0.238 & -0.014 & -0.010 \\
\hline $\mathrm{NEA}_{\mathrm{t}-2}$ & +0.153 & $0.014^{* *}$ & $0.017^{* * *}$ \\
\hline Population & +0.034 & 0.010 & $-0.029^{*}$ \\
\hline Density & +0.004 & 0.002 & $0.030^{* * *}$ \\
\hline Black & -0.004 & -0.001 & 0.021 \\
\hline Other & +0.034 & 0.007 & -0.004 \\
\hline Youth & -0.008 & $0.020^{* * *}$ & $0.052^{* * *}$ \\
\hline Elders & +0.008 & $-0.002^{*}$ & -0.001 \\
\hline College & +0.012 & 0.002 & 0.009 \\
\hline Income & -0.014 & $-0.011^{* *}$ & $-0.013^{* *}$ \\
\hline RGovGrid & -0.077 & $-0.007^{* *}$ & -0.006 \\
\hline DGovGrid & -0.038 & -0.001 & 0.000 \\
\hline RGovDiv & 0.000 & $0.000^{* * *}$ & $0.000^{* *}$ \\
\hline RUnified & +0.231 & 0.008 & -0.002 \\
\hline DUnified & -0.077 & -0.004 & -0.003 \\
\hline Turnout $(\%)$ & -0.024 & 0.004 & 0.003 \\
\hline Year & +4.000 & $-0.092^{* *}$ & $-0.252^{* * *}$ \\
\hline $\begin{array}{l}\text { State fixed } \\
\text { effects }\end{array}$ & & not included & -0.051 \\
\hline Total (predicted) & & -0.126 & -0.275 \\
\hline Total (actual) & & -0.276 & -0.276 \\
\hline
\end{tabular}

Note: ${ }^{* * * * * *}$ indicate the underlying parameter (from Noonan, 2007) is significantly different from 0 at the 1 , 5 , and $10 \%$ levels, respectively.

As Table 3 shows, some of the experienced changes do not conform to intuitions or perceptions. State revenues (inclusive of intergovernmental transfers and federal stimulus spending), for instance, did not decline during the recession - in fact they increased by almost 6\%. NEA grants to states also did not fall. Both of those fiscal variables predict increases in SAA spending over the recession but belie the severe fiscal austerity experienced. Real average income fell by only 1\%. Further, shifting party control in state governments predicts very little funding decline. The shift to more Republican control of state governments 
might have been expected to benefit SAA appropriations based on earlier findings, but it seems likely that such a pro-GOP shift did not in fact benefit SAA budgets.

What really predicted the large decline in funding (from Table 3) is more a combination of the mere passage of time and no compensatory growth in the other forces that prop up SAA appropriations. Four years alone account for a predicted $25.2 \%$ decline, per Model 2, for an average state. This was compounded by the inertia of previously declining SAA budgets (another 7\%). A decreasing share of youth in the population actually counteracted some of this decline, consistent with Benito et al.'s (2013) negative Youth effects. But, by and large, the other fiscal, socioeconomic, and political variables played minor roles in the Model 2 which fairly accurately predicted the large average budget reductions observed from 2007-2011 as an out-of-sample forecast.

Table 4: Old and new results from regression estimates of determinants of SAA budgets

\begin{tabular}{|c|c|c|c|c|c|c|c|c|}
\hline \multirow[b]{3}{*}{ Variable } & \multicolumn{4}{|c|}{ Model 1} & \multicolumn{4}{|c|}{ Model 2} \\
\hline & \multicolumn{2}{|c|}{ 1969-2002 } & \multicolumn{2}{|c|}{ 1969-2011 } & \multicolumn{2}{|c|}{ 1969-2002 } & \multicolumn{2}{|c|}{$1969-2011$} \\
\hline & Coef. & z-stat & Coef. & z-stat & Coef. & z-stat & Coef. & z-stat \\
\hline $\mathrm{SAA}_{\mathrm{t}-1}$ & $0.746^{* * *}$ & 27.48 & $0.814^{* * *}$ & 43.95 & $0.639^{* * *}$ & 17.40 & $0.747^{* * *}$ & 29.82 \\
\hline Revenue $_{t}$ & 0.101 & 1.31 & $0.096^{*}$ & 1.68 & $0.175^{* *}$ & 2.01 & $0.138^{* *}$ & 2.09 \\
\hline Revenue $_{\mathrm{t}-1}$ & 0.059 & 0.88 & 0.060 & 1.08 & $0.186^{* *}$ & 2.37 & $0.092^{*}$ & 1.69 \\
\hline Revenue $_{\mathrm{t}-2}$ & -0.054 & -1.26 & -0.050 & -0.99 & $0.062^{*}$ & 1.80 & 0.015 & 0.32 \\
\hline Debt $_{t}$ & -0.029 & -0.86 & $-0.068^{*}$ & -1.78 & -0.046 & -1.49 & -0.053 & -1.49 \\
\hline Debt $_{\mathrm{t}-1}$ & -0.039 & -1.46 & $-0.054^{*}$ & -1.82 & $-0.057^{*}$ & -1.92 & -0.042 & -1.41 \\
\hline Debt $_{t-2}$ & $0.052^{* *}$ & 1.99 & $0.073^{* *}$ & 2.07 & $0.060^{* *}$ & 2.11 & $0.071^{*}$ & 1.92 \\
\hline $\mathrm{NEA}_{t}$ & $0.128^{* *}$ & 2.13 & 0.051 & 1.33 & $0.105^{*}$ & 1.82 & 0.028 & 0.73 \\
\hline $\mathrm{NEA}_{\mathrm{t}-1}$ & -0.058 & -0.89 & -0.060 & -1.43 & -0.044 & -0.75 & -0.043 & -1.16 \\
\hline $\mathrm{NEA}_{\mathrm{t}-2}$ & $0.090^{* *}$ & 2.48 & $0.048^{*}$ & 1.74 & $0.114^{* * *}$ & 3.06 & $0.059^{* *}$ & 1.98 \\
\hline Population & 0.299 & 1.51 & $0.231^{*}$ & 1.90 & $-0.861^{*}$ & -1.69 & 0.537 & 1.21 \\
\hline Density & 0.529 & 0.92 & 0.097 & 0.06 & $6.750^{* * *}$ & 4.22 & $14.181^{* *}$ & 2.36 \\
\hline Black & 0.205 & 0.07 & 0.774 & 0.90 & -5.331 & -1.39 & -0.592 & -0.75 \\
\hline
\end{tabular}




\begin{tabular}{|c|c|c|c|c|c|c|c|c|}
\hline Other & 0.205 & 0.52 & 0.174 & 1.13 & -0.115 & -0.38 & -0.072 & 0.45 \\
\hline Youth & $-2.649^{* * *}$ & -2.73 & $-3.594^{* * *}$ & -4.74 & $-6.775^{* * *}$ & -4.01 & $-5.957^{* * *}$ & 5.60 \\
\hline Elders & $-0.191^{*}$ & -1.80 & $-0.210^{* *}$ & -2.11 & -0.168 & -1.25 & -0.089 & 0.68 \\
\hline College & 0.210 & 0.34 & -0.095 & -0.22 & 0.753 & 1.05 & -0.162 & 0.34 \\
\hline Income & $0.780^{* *}$ & 2.54 & $0.903^{* * *}$ & 4.61 & $0.898^{* *}$ & 2.53 & $0.835^{* * *}$ & 3.00 \\
\hline RGovGrid & $0.090^{* *}$ & 2.11 & $0.055^{*}$ & 1.85 & 0.074 & 1.50 & $0.070^{* *}$ & .27 \\
\hline DGovGrid & 0.017 & 0.40 & 0.001 & 0.03 & -0.005 & -0.11 & -0.011 & 0.33 \\
\hline RGovDiv & $0.095^{* * *}$ & 2.65 & $0.071^{* * *}$ & 2.71 & $0.083^{* *}$ & 2.08 & $0.084^{* * *}$ & 2.90 \\
\hline RUnified & 0.033 & 1.41 & -0.018 & -0.62 & -0.010 & -0.28 & -0.009 & 0.27 \\
\hline DUnified & 0.049 & 1.50 & 0.038 & 1.48 & 0.043 & 1.12 & $0.051^{*}$ & 1.69 \\
\hline Turnout (\%) & -0.164 & -1.33 & $-0.307^{* * *}$ & -3.16 & -0.125 & -0.87 & $-0.274^{* * *}$ & 2.74 \\
\hline Year & $-0.023^{* *}$ & -2.36 & $-0.029^{* * *}$ & -6.18 & $-0.063^{* * *}$ & -5.70 & $-0.051^{* * *}$ & 3.39 \\
\hline Term Year 1 & $-0.049^{*}$ & -1.96 & -0.021 & -1.05 & $-0.061^{* *}$ & -2.56 & -0.025 & -1.32 \\
\hline Term Year 2 & 0.020 & 0.77 & 0.032 & 1.51 & 0.014 & 0.54 & 0.027 & 1.34 \\
\hline Term Year 3 & 0.012 & 0.35 & 0.016 & 0.62 & 0.015 & 0.47 & 0.019 & 0.77 \\
\hline Origin Yeara & $0.0003^{* *}$ & 2.24 & $0.0002^{* * *}$ & 2.91 & 0.0001 & 0.44 & $0.003^{* *}$ & 2.47 \\
\hline$\underline{\text { BalanceBudga }}$ & $0.005^{*}$ & 1.94 & $0.003^{* *}$ & 2.23 & $0.021^{* * *}$ & 5.63 & 0.010 & 1.03 \\
\hline Number of obs. & 1521 & & 1972 & & 1521 & & 1972 & \\
\hline $\begin{array}{l}\text { Number of } \\
\text { groups }\end{array}$ & 50 & & 50 & & 50 & & 50 & \\
\hline Wald (df) & 15560.4 & & $20246.76(30)$ & & $2.45 \times 10^{10}($ & 52) & $3.41 \times 10^{9}(77)$ & \\
\hline$m_{2}$ & -0.61 & & -0.45 & & -0.78 & & -0.52 & \\
\hline Sargan's $s$ & 27.53 & & 1630.41 & & $<0.001$ & & 1741.62 & \\
\hline
\end{tabular}

Updating the data through 2011 allows a re-estimation of previous models with the larger sample inclusive of the Great Recession. Table 4 shows the new estimation results alongside the Noonan (2007) estimates based on the shorter timeframe, without (Model 1) and with state fixed effects (Model 2). ${ }^{6}$ Based on Model 1, the

\footnotetext{
${ }^{6}$ The diagnostic statistics reported in Table 4, the Sargan's $s$ (test for validity of instruments) and $m_{2}$ (test for secondorder autocorrelation), all possess suitably low values as in Noonan (2007), lending confidence that the Arellano-Bond approach remains appropriate for these data. The p-values for the Sargan tests for models 1 and 2 are 0.92 and 0.26 ,
} 
overall results with the updated data demonstrate similarity with the previous results but also a great deal of change. The effects of previous years' SAA funding and total state revenues look largely unchanged with the inclusion of new data. State debt levels now play a stronger role, with coefficients and $\mathrm{z}$ statistics each growing in absolute value. The role of NEA funding in attracting state appropriations is substantially diminished. Updating the sample has attenuated the effects of NEA grants in the present year and two years hence, so much so that the NEA funding variables are now jointly insignificant in Model 1. A few demographic factors still exhibit significant influence (e.g., youth population, income), whereas a few still have little or no explanatory power (e.g., population density, racial composition, education levels). The time trend coefficient is roughly unchanged even as the effect of electoral cycles has muted. The changes in political determinants of funding are perhaps the most dramatic. Voter turnout is now strongly associated with downward funding pressures, and the positive influence of Republican representation has faded. That recent years have heightened the negative voter turnout effect suggests that it is recent competitive electoral races, rather than civic culture, leading to funding cuts. Moreover, a unified Republican state government now looks like the worst situation for SAA appropriations. Relative to the omitted category of divided state government with a Democratic governor, Republican governors with a non-Republican legislature is good for SAA funding but perhaps not as good as it was before the most recent decade. The Tea Party's recent rise may account for weaker Republican support.

The fixed-effect model, Model 2, offers another opportunity to compare results based on the updated data. The state fiscal variables and especially lagged SAA appropriations play a similarly important role once state fixed effects are included. The jointly insignificant Debt variables in Model 2 suggests that their more important role in Model 1 may be driven by a few states' idiosyncrasies rather than a substantial role for state debt in determining SAA appropriations. As in Model 1, funding from the NEA is less important in the results using new data. (NEA variables are jointly insignificant in Model 2 with $\chi^{2}(3)=5.52, \mathrm{p}=0.14$.) The population density, share of youth in the state's population, and income remain important determinants here. 
Education levels remain an insignificant predictor, consistent with other studies of determinants of cultural expenditures (e.g., Benito et al. 2013) that find no education effect. The previous significant coefficients of the first year of a presidential term and balanced budget rules become insignificant when the sample is extended. Conversely, significant effects are now evident for the age of the SAA and for voter turnout rates. Voter turnout's stronger, negative effect in the state fixed-effect model points to important recent changes in turnout driving SAA funding. More active electorates, perhaps in recent battleground states and those experiencing more campaign expenditures (Geys 2006), tend to reduce state SAA appropriations.

Table 5's results offer two interesting directions for comparison. First, comparing the state-level fixed effects from Noonan (2007) with the most comparable fixed effects from Model 2 in Table 4 gives an indication of how state-level SAA "friendliness" looks different from the post-Great Recession vantage. As these fixed effects are persistent, time-invariant state-level effects, they ought not be changing as the data extend another decade. Yet, as the other parameters evolve and new patterns in the data are revealed, some states do exhibit marked shifts. Many states' see their fixed effects remain constant in terms of sign and significant even after updating the data. A large swing to the negative for Michigan is interesting to note. Conversely, large positive swings are apparent for Iowa, Kansas,, Oregon, Montana, South Carolina, and Tennessee. In a sense, the last decade has revealed these states to be differently hospitable to SAA appropriations than they once were. Second, comparing the state-level fixed effects to the high-profile cases of severe budget cuts, or threats of budget cuts, in Table 1 offers an interesting way to view how surprising (or typical) those large cuts are in those states. Some large cuts in states like South Dakota, Louisiana, Michigan, Washington, Wisconsin, and Florida appear consistent with generally lower SAA appropriations in those states. Yet the (newly) positive state fixed effect for Kansas $(\beta=0.0 .13$, $\mathrm{p}$-value $=0.041)$ sticks out as noteworthy in light of the highly publicized dismantling of their SAA recently. 
Table 5: State fixed-effect estimates from Model 2

\begin{tabular}{|c|c|c|c|c|c|c|c|}
\hline State & Old FE & New FE & $\mathrm{z}$ & State & Old FE & New FE & $\mathbf{z}$ \\
\hline $\mathrm{AK}$ & -0.019 & $-0.019^{*}$ & -1.93 & MT & $-0.038^{* * *}$ & -0.003 & -0.50 \\
\hline $\mathrm{AL}$ & -0.016 & 0.006 & 1.11 & $\mathrm{NC}$ & $-0.022^{*}$ & -0.010 & -1.22 \\
\hline AR & $-0.025^{* *}$ & $-0.012^{* *}$ & -2.55 & ND & -0.004 & 0.006 & 1.59 \\
\hline $\mathrm{AZ}$ & 0.013 & -0.009 & -0.55 & $\mathrm{NE}$ & omitted & omitted & \\
\hline CA & -0.017 & $-0.017^{* *}$ & -1.98 & $\mathrm{NH}$ & $-0.021^{*}$ & 0.002 & 0.33 \\
\hline $\mathrm{CO}$ & $-0.023^{*}$ & -0.011 & -1.22 & $\mathrm{NJ}$ & -0.011 & $-0.023^{* *}$ & -2.52 \\
\hline $\mathrm{CT}$ & -0.011 & -0.004 & -0.55 & NM & 0.007 & -0.018 & -1.52 \\
\hline $\mathrm{DE}$ & -0.008 & -0.009 & -1.11 & NV & 0.019 & 0.016 & 1.25 \\
\hline FL & $-0.052^{*}$ & $-0.032^{* * *}$ & -3.06 & NY & 0.010 & -0.009 & -0.51 \\
\hline GA & -0.017 & $-0.016^{*}$ & -1.76 & $\mathrm{OH}$ & -0.018 & $-0.022^{*}$ & -1.74 \\
\hline $\mathrm{HI}$ & -0.015 & 0.005 & 0.55 & OK & -0.005 & 0.005 & 1.09 \\
\hline IA & -0.009 & $0.011^{* *}$ & 2.32 & OR & -0.015 & $0.015^{* *}$ & 2.51 \\
\hline ID & -0.004 & 0.005 & 0.53 & $\mathrm{PA}$ & -0.001 & -0.003 & -0.55 \\
\hline IL & 0.002 & 0.003 & 0.46 & RI & $-0.026^{*}$ & 0.002 & 0.35 \\
\hline IN & 0.014 & 0.001 & 0.20 & SC & $-0.031^{* *}$ & -0.003 & -0.42 \\
\hline $\mathrm{KS}$ & -0.008 & $0.013^{* *}$ & 2.05 & SD & -0.015 & $-0.017^{* *}$ & -2.34 \\
\hline KY & -0.019 & 0.005 & 0.80 & TN & $-0.026^{* *}$ & 0.003 & 0.60 \\
\hline LA & -0.011 & $-0.014^{* * *}$ & -3.48 & $\mathrm{TX}$ & -0.013 & 0.005 & 0.92 \\
\hline MA & -0.024 & $-0.028^{* * *}$ & -3.06 & UT & $-0.023^{*}$ & -0.008 & -1.01 \\
\hline MD & -0.009 & $-0.014^{*}$ & -1.84 & VA & 0.010 & 0.016 & 0.30 \\
\hline $\mathrm{ME}$ & $-0.035^{* * *}$ & $-0.015^{* * *}$ & -3.02 & VT & $-0.049^{* *}$ & $-0.023^{* * *}$ & -4.68 \\
\hline MI & 0.009 & $-0.010^{* *}$ & -2.05 & WA & -0.014 & $-0.028^{* * *}$ & -2.69 \\
\hline $\mathrm{MN}$ & -0.001 & 0.009 & 1.41 & WI & 0.003 & -0.012 & -1.27 \\
\hline $\mathrm{MO}$ & -0.014 & 0.007 & 1.09 & WV & -0.019 & omitted & \\
\hline MS & -0.017 & -0.003 & -0.73 & WY & -0.014 & omitted & \\
\hline
\end{tabular}

The importance of state fixed effects in Model 2 raises several issues about state political culture and adaptability to the recent fiscal crisis. How well positioned an SAA is, within the state government and with respect to influential constituencies, can affect how its funding fared in the past decade. Noonan (2007) tests whether the SAA's placement in state government (e.g., in a tourism department, in the governor's office) 
influenced appropriations growth rates and finds no effect. In recent years, however, several SAAs have been relocated, notably to economic development or tourism departments (NASAA 2014). Including agency placement indicators in the fixed-effects model identifies the effects of placement based on changes in location, and this approach yields significant coefficients only for tourism. Being relocated to a tourism department does not bode well for future SAA appropriations $(\beta=-0.11, z=-2.06)$. Updated estimates in Table 4 indicate that newer SAAs have fared better over time, perhaps because they are better adapted to current political demands. That the new Turnout effect remains larger even when controlling for state fixed effects reinforces the responsiveness to recent political forces above and beyond a state's political culture. Although Benito et al. (2013) and Bertelli et al. (2014) find evidence of politically strategic cultural spending, SAAs spread their spending so widely (Rosenstein et al. 2013) that it can leave them vulnerable and without political champions. SAAs that diffused their grants more widely from 2008 to 2010 per Rosenstein et al. (2013) tended to experience more severe budget cuts over that time. ${ }^{7}$

\section{Discussion and Conclusion}

The hard times for arts agencies leave many in the arts community wondering if the Great Recession is ushering in a new, anemic equilibrium for public arts funding. By revisiting the Noonan (2007) analysis, and updating it, the results highlight some major positive and normative concerns for understanding public arts funding in the U.S. system and more generally. From today's vantage, we can observe how well that model predicts the changes actually experienced. This comparison shows that the severe budget cuts experienced in the wake of the recession are largely to be expected, but there are some interesting shortcomings in the previous results, which points to a shift in the determinants of public arts funding in the US.

Overall, several key findings emerge. First, the accuracy of the out-of-sample prediction estimated using only pre-2003 data indicates that (a) the recent economic crisis has not fundamentally altered public funding

\footnotetext{
${ }^{7}$ Rosenstein et al.'s (2013) state "equity score" is negatively correlated with $\left[S A A_{2010}-S A A_{2008}\right], \varrho=-0.54(\mathrm{p}<0.001)$.
} 
patterns, and (b) idiosyncratic state-specific funding tendencies play an important role. Second, many of the significant determinants identified by Noonan (2007) persist throughout the upheaval of the Great Recession. These include state revenues and previous year SAA appropriations, youth population and household income, and a time trend, as shown in Table 4. These fiscal and demographic factors are common threads in US public arts funding stretching across states and across major economic cycles. Third, extending the data to encompass the Great Recession also points to some notable changes, such as the fading influence of NEA grants and the stronger influence of voter turnout. It is too soon to see all of the impacts of the recent deep recession, and some aspects might not be captured by the statistical models here. For instance, the important state fixed effects highlight the opportunity for future research to unpack persistent state-specific factors like its cultural and philanthropic traditions.

Identifying the determinants of public arts funding levels raises several important questions about public arts support, both positive and normative. There are questions of federalism and subsidiarity (i.e., the principle of devolving political decisions to the lowest level), as understanding how different levels or jurisdictions of governments complement and substitute for one another in funding the arts. Results here point to an evolving relationship between federal and state funds. The history of NEA funding and SAA appropriations shows how, in a matter of a few years, the arts transformed from a funding category that most states saw fit to overlook entirely to one where appropriations greatly exceeded the minimum matching requirements. Noonan's (2007) older data confirm the role of federal arts funding in seeding what is now a much larger source of direct government expenditures on the arts. The updated results indicate a weaker "flypaper effect" (i.e., that federal grants to states stick where they land rather than see states offset them by decreasing appropriations) for NEA grants. That some states would eliminate their SAAs and forgo NEA matching grants, even in the face of difficult budgetary times, is consistent with this weaker federal role. It may also mark a shift to more rational state arts spending. Political ideology in the US does not play a simple role (e.g., Republicans do not appear consistently opposed to arts funding, major funding cuts are not confined to states with strong Tea Party support). It may not matter much at all, like Getzner (2002, this issue) and 
Benito et al. (2013) find. Rather the very strong role of lagged SAA appropriations underscores a path dependency in public arts funding and suggests a "stickiness" and inertia in funding that belies an approach to public arts funding driven by either permanent conditions or by contemporary circumstances. "Tipping points" and momentum can be particularly important in this domain. Whether this makes the arts particularly vulnerable or is merely a reality that artists and arts organizations should plan for is worth considering in future work.

It is not all "animal spirits" that drive public arts spending. Spontaneous optimism (or pessimism) and emotional drives may guide some public art spending, but the models estimated here identify systemic, quantitative patterns as well. Some traditional public finance and socioeconomic variables play prominent roles (e.g., revenues, household income, voter turnout). This indicates a "mixed bag" for an implicit public arts funding model - partly economics, partly politics, and partly shifting cultural forces.

A generally important aspect of public arts funding agencies is their degree of independence from political forces, how much autonomy they enjoy in allocating funds to different endeavors, and how that might be interdependent with the amount of resources that they have at their disposal. (See Bertacchini and Dalle Nogare, in this issue of Poetics, for a broader international discussion.) Oft times, autonomy is traded off against resource levels (from the treasury). Less ability to leverage NEA grants into greater SAA appropriations in recent years may imply greater autonomy from federal sources. This is consistent with the decline in the NEA's policymaking primacy and a more democratic cultural federalism (Mulcahy 2002). Serving broad constituencies and avoiding elitist connections (e.g., no College effect) also retains some political independence for SAAs but does not yield bigger budgets. Given the vagaries (and volatility) of politicians appropriating funds, discussions in the U.S. are turning to reducing direct political influence over public funding streams (e.g., by linking budgets to earmarked fees or taxes like the "percent for art" programs observed in half of the US states) (Clapp 2012). 
The political economy of SAA appropriations is complex. Some things look fairly stable, even in the midst of "historic" levels of tumult. But the models here show no single funding formula and much variation is unaccounted for. The US case for SAAs reveals a highly variable and surprisingly fluid cultural policy, and one that is substantively responsive to major political and fiscal circumstances. These results confirm a close relationship between political economy factors and arts support. It is not just that economic forces influence artists; economic forces also influence our cultural policies. Better understanding both can help us craft better policies and better anticipate future changes. 


\section{References:}

Arellano, Manuel and Stephen Bond. 1991. "Some Tests of Specification for Panel Data: Monte Carlo Evidence and an Application to Employment Equations." Review of Economic Studies. 58(2): 277-297.

Benito, Bernardino, Francisco Bastida, and Cristina Vicente. 2013, "Municipal elections and cultural expenditure." Journal of Cultural Economics. 37(1): 3-32.

Bertacchini, Enrico and Chiara Dalle Nogare. Forthcoming. "Emerging modes of public cultural spending: Direct support through production delegation." Poetics. This issue.

Bertelli, Anthony M., Jennifer M. Connolly, Dyana P. Mason, and Lilian C. Conover. 2014. "Politics, management, and the allocation of arts funding: evidence from public support for the arts in the UK." International Journal of Cultural Policy. 20(3): 341-359.

Clapp, Henry. 2012. “State Arts Agency Supplemental Funding Strategies.” Last accessed 3 December 2013: http://www.nasaa-arts.org/Research/Funding/PolicyBrief-SupplementalFunding.pdf

Getzner, Michael. 2002. "Determinants of Public Cultural Expenditures: An Exploratory Time Series Analysis for Austria." Journal of Cultural Economics. 26(4): 287-306.

Getzner, Michael. Forthcoming. "Cultural politics: Exploring determinants of cultural expenditure." Poetics. This issue.

Geys, Benny. 2006. "Explaining Voter Turnout: A Review of Aggregate-Level Research.” Electoral Studies. 25: 637-663.

Gordon, Tracy. 2012. State and Local Budgets and the Great Recession. Washington, DC: The Brookings Institution. Accessed on 29 October 2013 at: http://www.brookings.edu/research/articles/2012/12/state-local-budgets-gordon

Lowell, Julia F. 2004. State Arts Agencies 1965-2003: Whose Interests to Serve? Santa Monica, CA: RAND Corporation.

Moore, Mark H. and Gaylen Williams Moore. 2005. Creating Public Value through State Arts Agencies. Minneapolis, MN: Arts Midwest.

Mulcahy, Kevin V. 2002. "The State Arts Agency: An Overview of Cultural Federalism in the United States." Journal of Arts Management, Law, and Society. 32(1): 67-80.

NASAA (National Assembly of State Arts Agencies). 2011. "State Arts Agency Funding and Grant Making." Last accessed 15 November 2013: http://www.nasaa-arts.org/Research/GrantMaking/2011 funding and grantmaking.pdf

NASAA (National Assembly of State Arts Agencies). 2014. "State Arts Agency Placement: Frequently Asked Questions.” Last accessed 1 December 2014: http://www.nasaaarts.org/Research/Structure/SAAPlacementFAQ.pdf

NEA (National Endowment for the Arts). 2 012. How the United States Funds the Arts. Washington, DC: National Endowment for the Arts. 
Nogare, Chiara Dalle, and Matteo Galizzi. 2011. “The political economy of cultural spending: evidence from Italian cities." Journal of Cultural Economics. 35(3): 203-231.

Noonan, Douglas S. 2007. "Fiscal Pressures, Institutional Context, and Constituents: A Dynamic Model of States' Arts Agency Appropriations," Journal of Cultural Economics 31(4): 293-310.

Oliff, Phil, Chris Mai, and Vincent Palacios. 2012. "States Continue to Feel Recession's Impact." Center on Budget and Policy Priorities report. Last accessed 1 December 2014: http://www.cbpp.org/files/28-08sfp.pdf

Pogrebin, Robin. 2011. “Arts Outposts Stung by Cuts in State Aid.” New York Times C1. 2 August 2011.

Rosenstein, Carole, Vanessa Riley, Natalia Rocha, and Tyler Boenecke. 2013. "The distribution and policy implications of US state government general operating support to the arts and culture: Lessons from the great recession." Cultural Trends. 22(3-4): 180-191.

Schuster, J. Mark. 2002. "Sub-National Cultural Policy--Where the Action Is: Mapping State Cultural Policy in the United States." International Journal of Cultural Policy. 8(2): 181-196.

Werck, Kristien, Bruno Heyndels, and Benny Geys. 2008. “The impact of 'central places' on spatial spending patterns: evidence from Flemish local government cultural expenditures.” Joumal of Cultural Economics 32(1): 35-58. 